\title{
Microstructure and mechanical properties of hetero-designed Ti-25Nb-25Zr alloy fabricated by powder metallurgy route
}

\author{
B. Sharma ${ }^{\dagger, 1}$, K. Nagano ${ }^{2}$, M. Kawabata ${ }^{3}$, K. Ameyama ${ }^{3}$ \\ †bhupen@fc.ritsumei.ac.jp

\begin{abstract}
${ }^{1}$ Ritsumeikan University Research Organization of Science and Technology, 1-1-1 Noji-Higashi, Kusatsu, Shiga, Japan
${ }^{2}$ Graduate School of Science and Engineering, Ritsumeikan University, 1-1-1 Noji-Higashi, Kusatsu, Shiga, Japan

Kusatsu, Shiga, Japan
\end{abstract} \\ ${ }^{3}$ Department of Mechanical Engineering, Faculty of Science and Engineering, Ritsumeikan University, 1-1-1 Noji-Higashi,
}

The harmonic structured (HS) materials have a heterogeneous microstructure consisting of bimodal grain size together with a controlled and specific topological distribution of ultra-fine grains ("Shell") and coarse-grains ("Core") areas. They have excellent strength combined with good ductility due to their unique heterogeneous "three-dimensionally (3D) gradient microstructure", the two properties being rather an antagonist from the classical metallurgy point of view. In the present study, HS Ti-25Nb-25Zr alloy (mass \%), compacts were successfully fabricated by a powder metallurgy method consisting of controlled mechanical milling (MM) of pre-alloyed Ti-25Nb-25Zr (TNZ) powder, followed by Spark Plasma Sintering. The MM leads to the severe plastic deformation at the powder particle surface. As a result, bimodal grains, with ultra-fine grains at the particle surface, and coarse-grains at the powder core, was achieved. After sintering of MM powder, the TNZ compacts with HS was achieved. The HS TNZ exhibited higher strength together with acceptable ductility as compared to the homogeneous microstructured TNZ alloy fabricated by SPS of as-received TNZ powder. The systematic characterization was done using Scanning Electron Microscope (SEM) equipped with a backscattered detector (BSE), Electron Back Scatter Diffraction (EBSD) and Energy Dispersive X-ray spectroscopy (EDX), XRD, and tensile testing. It is shown that different powder conditions led to significantly different microstructures. Also, it was observed that the high ductility and low strength was achieved for the compact prepared from as-received powder whereas a good combination of strength and ductility was achieved for the specimen prepared from MM of as-received powder.

Keywords: harmonic structure, powder metallurgy, spark plasma sintering, $\beta$-Titanium alloys, Ti-Nb-Zr alloys.

\section{Introduction}

$\beta$-Ti alloys, containing nontoxic elements such as $\mathrm{Ti}, \mathrm{Nb}$, $\mathrm{Zr}$, Sn, and Ta, are one of the most illustrious materials for biomedical orthopedic implants owing to their superior biocompatibility, and excellent mechanical properties [1-7]. One of these contemporary biomedical grade $\beta$-type Ti alloy is a newly developed $\mathrm{Ti}-25 \mathrm{Nb}-25 \mathrm{Zr}$ (mass \%) alloy [8-11]. As the main disadvantage of $\beta$-type Ti alloys is their low strength which can be improved by grain refinement. However, it reduces the ductility. Therefore, from a classical metallurgical point of view, the grain size and strength are considered as antinomies. It remains a challenge for researchers to achieve high strength in materials without compromising their ductility. In recent years, it has been demonstrated that the materials with bimodal grain size distribution exhibit superior mechanical properties. However, in general, there are several issues associated with the control of bimodal microstructure when preparing bulk materials through conventional processing approach consisting of severe plastic deformation and controlled annealing.

The powder metallurgy (PM) based approach was found to be suitable to prepare bulk metals and alloys with a tailored bimodal microstructure. Recently, Ameyama and co-workers proposed an exquisite microstructural design with a bimodal grain size distribution, called "Harmonic Structure" (HS). In HS, coarse-grained regions ("Core") are enclosed in a continuously connected three-dimensional network of regions with fine-grained regions ("Shell"). The advantage of such gradient heterogeneous structure is the improvement of mechanical performance.

In general, the blended elemental (BE) and pre-alloyed (PA) powder techniques are two principle approaches to produce Ti alloy powders. The BE and PA powders have been used to prepare PM Ti-based alloy components in aerospace application since the 1980s [12]. Plasma Rotating Electrode Process (PREP) is one of the common technique, which is a crucible-free approach and can produce highpurity metal and pre-alloyed spherical-particle powders. In the past 20 years, the most common and only viable method of making high-purity titanium alloy powder with spherical morphology is PREP technique [13]. Recent studies [14-20] have demonstrated that various components with full density and good mechanical properties can be obtained by SPS of PA powders. As compared with the BE, the PA powder compacts exhibit better properties [21].

Therefore, considering the above-mentioned factors of proposed powder metallurgy method (i.e., Simple, 
controlled and cost-effective process, and balance of mechanical properties) the Ti-25Nb-25Zr alloy, with homogeneous and heterogeneous structure, was fabricated from pre-alloyed TNZ powder. The microstructure, phase composition, and the mechanical properties of the fabricated $\mathrm{Ti}-25 \mathrm{Nb}-25 \mathrm{Zr}$ alloy compacts were investigated. Obviously, the proposed microstructural design in $\mathrm{Ti}-25 \mathrm{Nb}-25 \mathrm{Zr}$ alloy would be crucial in designing a suitable processing strategy to manufacture economical components with tailor-made properties.

\section{Materials and Methods}

As-received pre-alloyed PREP Ti-25Nb-25Zr powder (further referred as "TNZ-IP powder") had an average particle size approximately $220 \mu \mathrm{m}$. To prepare $\mathrm{Ti}-25 \mathrm{Nb}-25 \mathrm{Zr}$ compacts with a homogeneous microstructure, the TNZ-IP powder was sintered via Spark Plasma Sintering (SPS) under the conditions mentioned in Table 1 . The cross-sectional microstructure of the TNZ-IP powder is shown in Fig. 1a. It has smooth spherical shape with dendritic microstructure.

To prepare TNZ compacts having bimodal microstructure ("HS") of coarse and fine grains, the TNZ-IP powder was mechanically milled (MM) for $72 \mathrm{ks}$ (further presented as TNZ-72 MM powder"). The MM was carried out under argon atmosphere using the planetary ball mill, with SUS balls and vials, operating at a speed of $200 \mathrm{rpm}$ and ball-topowder weight ratio $5: 1$. The sintering conditions of SPS are shown in Table 1.

The cross-sectional microstructure of the TNZ-72MM powder particles is shown in Fig. 1b. The appearance at the surface of the powder particle is significantly different as compared to the center. It is clear that longtime MM induces severe plastic deformation (SPD) at the outer surface of the powder particles (Fig. 1b). Therefore, the featureless SPD region at the surface may correspond to the "Shell" whereas undeformed regions at the inner area of MM-powder may correspond to the "Core". For the TNZ-72MM powder, the depth of deformation from outer surface is $\sim 50 \pm 6 \mu \mathrm{m}$. Therefore, it is revealed that, after MM, the severe plastic deformation was limited to a particular depth range.
Table 1. The processing parameters of Spark Plasma Sintering (SPS).

\begin{tabular}{|c|c|}
\hline Heating / Cooling rate & $100 \mathrm{~K} / \mathrm{Min}$ \\
\hline Holding Time & $1.8 \mathrm{ks}$ \\
\hline Temperature & 873,1073 and $1273 \mathrm{~K}$ \\
\hline Pressure & $50 \mathrm{MPa}$ \\
\hline
\end{tabular}

It has already been shown that in the case of mechanical milling of pure $\mathrm{Ti}$, stainless steel, $\mathrm{Ti}-6 \mathrm{Al}-4 \mathrm{~V}$ powders, nanograin structures and significant amounts of dislocations are formed on the plastically deformed surface area of the powder particles [22-24]. Therefore, in this study, the authors presume that the similar characteristics of TNZ-72MM powders may also be due to grain refinement, at shell area, occurs via deformation, fragmentation, and subdivision of the initial dendritic microstructure due to the SPD via MM. Therefore, the ultrafine-grain structures are formed in the TNZ-72MM powder surface in the same way. As a result, the controlled MM leads to the formation of a bimodal microstructured powder particle, i.e. (i) plastically deformed "shell" region in the vicinity of the surface of the particle, and (ii) non-deformed "core" inner region with retained dendritic characteristics.

All the powders were consolidated via Spark Plasma Sintering (Dr. Sinter, Sumitomo Coal Mining Co. Ltd., Japan) under high vacuum conditions $(\sim 10-3 \mathrm{~Pa})$, using graphite die and punch. The disc-shaped compacts with dimensions $20 \mathrm{~mm}$ (diameter) $\times 5 \mathrm{~mm}$ (height) were obtained after the SPS process. The sintered compacts are named as per their initial conditions and sintering temperatures. The compacts prepared from sintering of TNZ-IP-Powder at 873, 1073, and $1273 \mathrm{~K}$ temperatures are referred as TNZ-IP-873, TNZ-IP-1073, and TNZ-IP-1273 compacts, respectively whereas those prepared from TNZ-MM powder at 1073, and $1273 \mathrm{~K}$ temperatures are referred as TNZ-MM-1073, and TNZ-MM-1273 compacts.

The phase analysis was performed by X-ray Diffraction (XRD) method using $\mathrm{Cu}_{\mathrm{Ka}}(\lambda=1.5406 \AA)$ radiation. The microstructural characterization was carried out by Scanning Electron Microscope (SEM) equipped with Back Scattered Electron (BSE) and Electron Backscattered

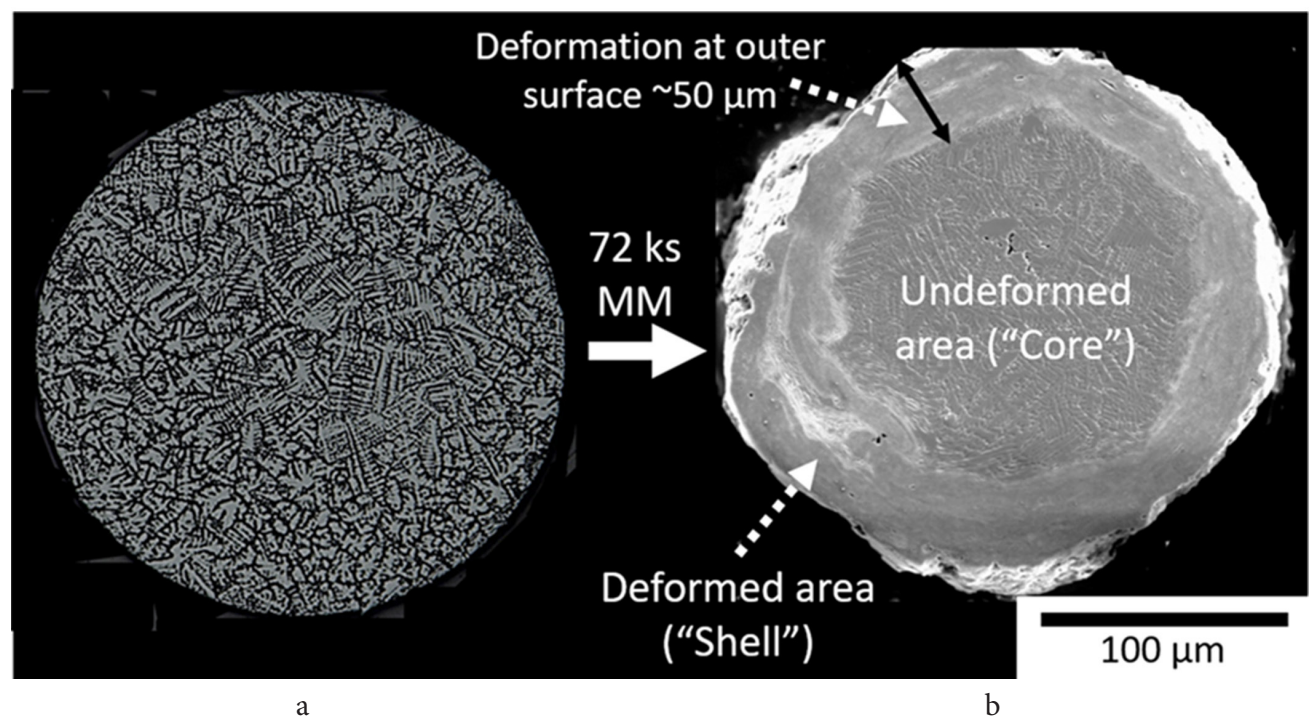

Fig. 1. The cross-sectional microstructure of TNZ-IP (a) and TNZ-72MM powder (b). 
Diffraction (EBSD) facilities. The Primary elemental characterization was carried out by Energy Dispersive $\mathrm{X}$-ray Spectroscopy (EDS) technique. The grain size analysis was performed using the line intercept method on at least five images for each value to avoid experimental scatter. EBSD data were processed in an HKL Channel 5 software package. The samples for SEM were prepared via a standard metallographic process (mechanically ground up to 2000 with $\mathrm{SiC}$ papers and mirror polished with Struers OP-S emulsion with the addition of $\mathrm{H}_{2} \mathrm{O}_{2}$ ).

The mechanical properties of the specimens were analyzed by tension tests carried out at an initial strain rate of $5.6 \times 10^{-4} \mathrm{~s}^{-1}$ using specimens with gauge dimensions of $3 \times 1 \times 1(\mathrm{~mm})$. At least three samples were considered to measure and calculate the average strength and elongation of as-fabricated $\mathrm{Ti}-25 \mathrm{Nb}-25 \mathrm{Zr}$ alloy specimens.

\section{Results and Discussion}

The XRD pattern of TNZ-IP powder and its 72MM powder is shown in Fig. 2. All XRD patterns revealed the single $\beta$-phase only that also confirmed the absence of any external impurities of oxidation. However, compared to the TNZ-IP powder the peak intensity and peak width of TNZ-72MM powder were notably changed. It was noted that, after MM, the intensities of the diffraction peaks are reduced and diffraction peaks are broadened. In general, the intensity reduction and broadening of a peak can be directly attributed to the severe plastic deformation (SPD) of powder. The SPD leads to grain size reduction and accumulated mechanical strains [25]. The Williamson-Hall method [26] was used to analyze the relative peaks in order to relate the broadening in the XRD peaks to the crystallite size and lattice strain of IP and MM powders. Assuming lattice strain to be uniform in all crystallographic directions, X-ray diffraction line broadening was studied using following Williamson-Hall uniform deformation equation.

$$
\beta \cos \theta_{h k l}=\left[\frac{K \lambda}{L}\right]+\left[4 \varepsilon \sin \theta_{h k l}\right]
$$

where $K$ is the shape factor $(\sim 0.9), \lambda$ is the $\mathrm{X}$-ray wavelength $\left(\mathrm{CuK}_{\alpha}-1.5406 \AA\right), \theta_{h k l}$ is the Bragg angle and $L$ is crystallite size, $\varepsilon$ is lattice strain. The first five most intensive diffraction peaks; (110), (200), (211), (220) and (310) were used to construct a linear plot of $\beta \cos \theta_{h k l}$, as a function of $4 \varepsilon \sin \theta_{h k l}$ the crystallite size $L$ may be estimated from the intersection with the vertical axis $\left[\frac{K \lambda}{L}\right]$ and the lattice strain $\varepsilon$ from the slope of the line. The measured crystallite size and accumulated lattice strain for the TNZ-IP powder is $58 \mathrm{~nm}$, and $1 \pm 0.8 \%$, respectively whereas for the TNZ-72MM powder it is $24 \mathrm{~nm}$, and $23 \pm 13 \%$, respectively. It is clear that longtime MM leads to the reduction in crystallite size and significant accumulation of mechanical strain. The high fraction of accumulated lattice strain is mainly associated with the introduction of lattice imperfections such as grain boundaries, dislocations, etc., during the SPD process.

The XRD patterns of sintered TNZ compacts are shown in Fig. 2 b. It can be seen that there are no significant differences in XRD patterns of TNZ compacts prepared at different sintering temperatures. The clear diffraction peaks suggest that all the samples have similar phase compositions and mainly consist of single $\beta$-phase.

Fig. 3 shows the EBSD micrographs for the TNZ-IP compacts subjected to SPS at different temperatures, where the black lines represent high-angle grain boundaries with misorientations greater than $15^{\circ}$. All three compacts exhibited the equiaxed type of microstructure which is a typical characteristic associated with the formation of $\beta$ microstructure in the TNZ alloy. It is clear from the microstructure of the sample sintered at $873 \mathrm{~K}$, Fig. $3 \mathrm{a}$, that densification is incomplete, as evidenced by the presence of porosity in the samples. The microstructural features of the samples sintered in the range of $1073-1273 \mathrm{~K}$ shows the $\beta$-Ti (bcc) matrix without observable porosities indicating complete densification together with a comparatively higher density of the TNZ-IP-1073, TNZ-IP-1273 compacts. The average grain size of TNZ-IP-873, TNZ-IP-1073, TNZ-IP-1273 compacts was approximately 20, 85 and $800 \mu \mathrm{m}$, respectively. The average grain size significantly increased with increasing in sintering temperature which indicated that a significant grain growth occurs during spark plasma sintering. As mentioned above, a significant residual porosity was noticed after sintering at $873 \mathrm{~K}$ (Fig. 3 a). Therefore, to ensure the effective compaction and high density in the harmonic structured TNZ compacts,

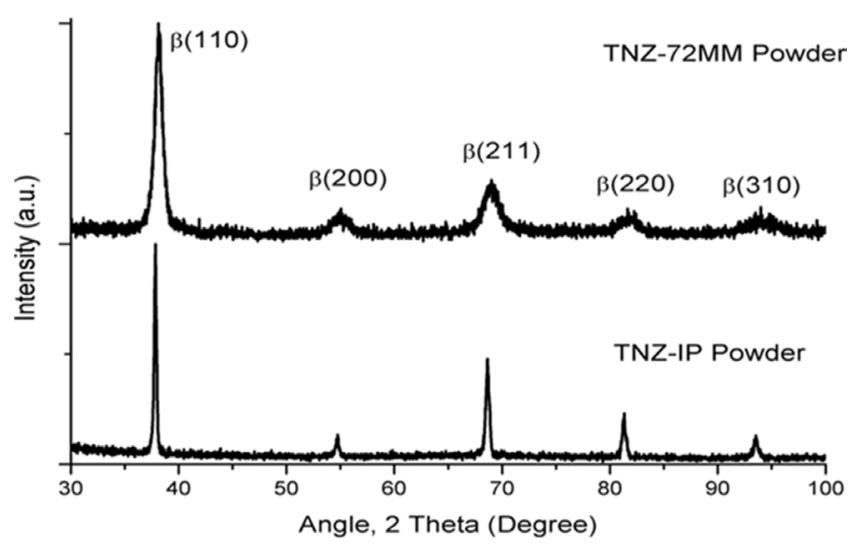

a

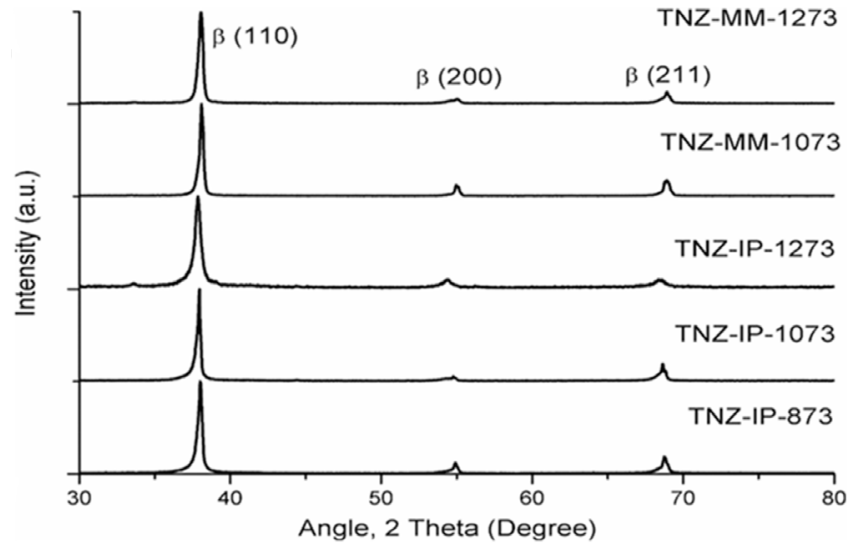

b

Fig. 2. The XRD pattern of TNZ-IP, and TNZ72 powders (a), and their compacts prepared at different temperatures (b). 
the sintering of TNZ-72MM powder was carried out at higher sintering temperatures of $1073 \mathrm{~K}$, and $1273 \mathrm{~K}$.

Fig. 4 displays the representative EBSD micrographs of TNZ-MM-1073, and TNZ-MM-1273 compacts prepared, from TNZ-72MM powder, at $1073 \mathrm{~K}$ and $1273 \mathrm{~K}$, respectively. As similar to the TNZ-IP compacts (Fig. 3b, c), the TNZ-MM-1073 and TNZ-MM-1273 compacts exhibited equiaxed grained structure. It is also to be noted that the equiaxed structure in Ti-based alloys has been reported to possess a better combination of low elastic modulus and higher strength compared to the lamellar or acicular structure [27]. However, the TNZ-MM compacts contained two different topological distribution of grains; (a) region with fine grains, and (b) comparatively coarse grains. In particular, interestingly, the regions of fine grains formed a continuously connected network structure that surrounded the coarse grains in a network-type arrangement. This threedimensionally continuous connected network structure can be referred to as a "Harmonic Structure" design (Fig. 4).
It would be worth emphasizing that the regions with fine and coarse grains correspond to the severely deformed surface and relatively non-deformed inner regions of the TNZ-72MM powder, respectively. For TNZ-MM-1073 compact, the mean grain size at a "shell" was approximately $4 \pm 2 \mu \mathrm{m}$ whereas at the "core" it was approximately $80 \pm 10 \mu \mathrm{m}$. The presence of the finer equiaxed grains in the shell region indicates that the recovery, recrystallization and/or grain growth processes were operative in the severely deformed region of the TNZ-72MM powder particles, during SPS. However, unlike large grain growth in TNZ-IP-1273 compact (Fig. 3c), it is interesting to note that a network-type arrangement was still observed even after sintering at a sufficiently elevated temperature of 1273 K. For TNZ-MM-1273 compact, the mean grain size at a "shell" was approximately $27 \pm 10 \mu \mathrm{m}$ whereas at the "core" it was approximately $160 \pm 20 \mu \mathrm{m}$. The difference in the grain size of the core and shell regions is an interesting and peculiar feature. These microstructural characteristics can be related to the degree of plastic deformation from the surface of the

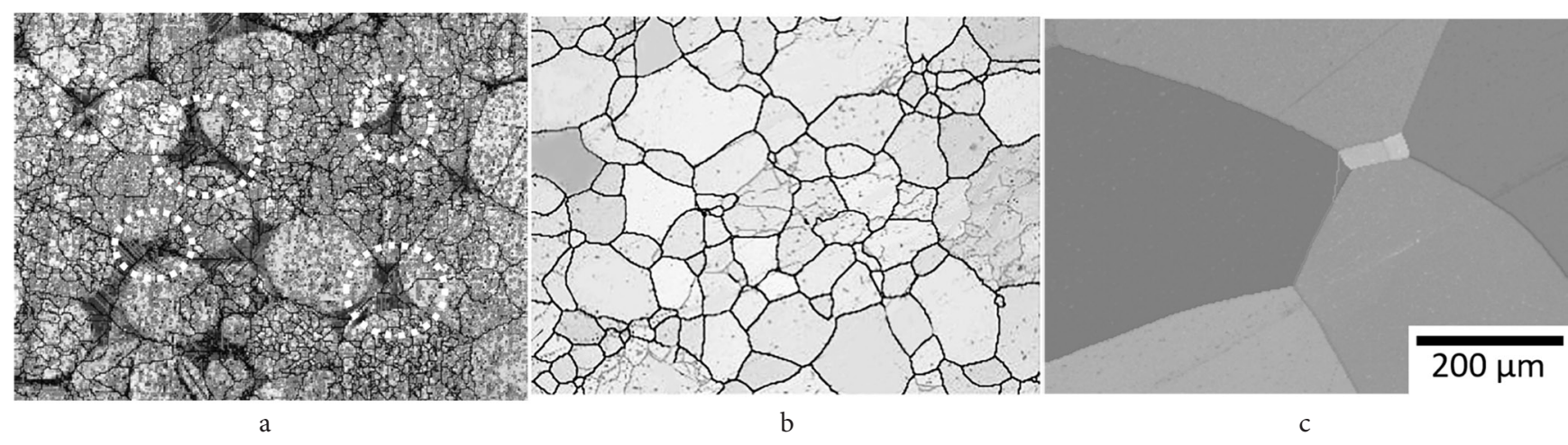

Fig. 3. SEM images of TNZ-IP-873 (a), TNZ-IP-1073 (b) and TNZ-IP-1273 (c) compacts. (The residual porosities are highlighted by white circles).

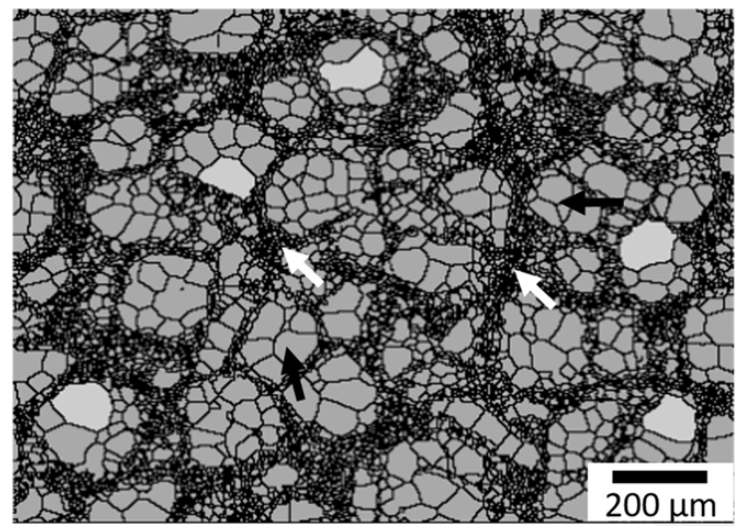

a

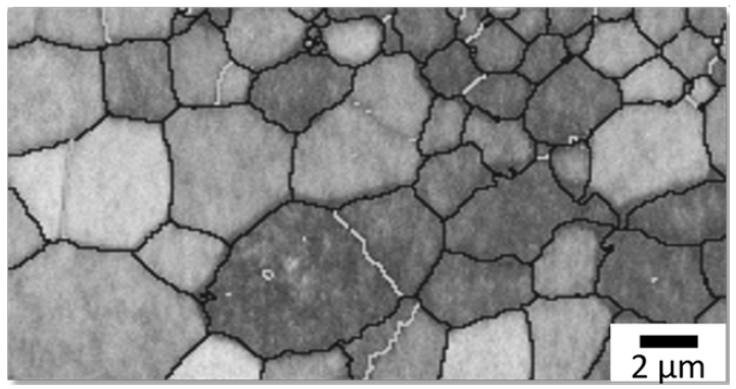

$\mathrm{b}$

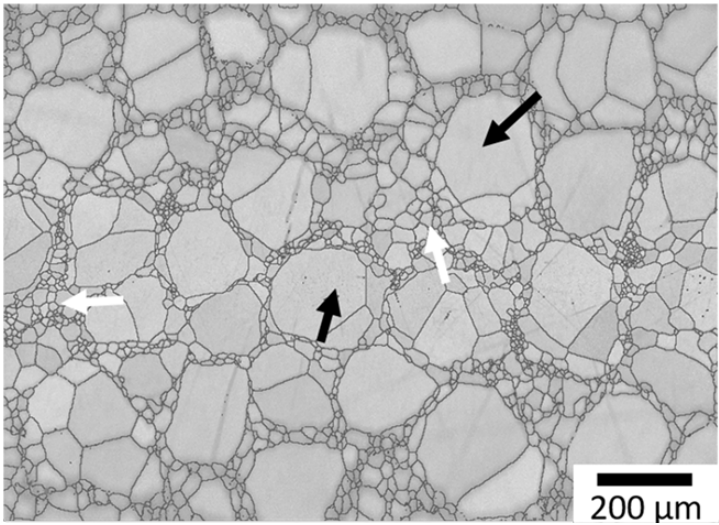

c

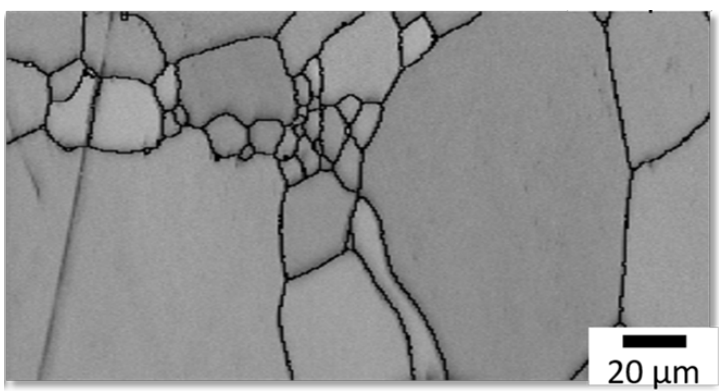

d

Fig. 4. EBSD band contrast images of TNZ-MM-1073 (a, b), and TNZ-MM-1273 (c, d) compacts. (The "fine-grained "Shell" regions are shown at higher magnifications also (c, d)). (The Core and Shell of network-structure are shown by black and white arrows, respectively). 
TNZ-72MM powder and the other various factors affecting the formation of nucleation and growth of the strain-free grains inside core regions. Also, it can be noticed that with increasing sintering temperature, the grain growth occurs. The fraction of fine-grained shell was estimated by image analysis. The shell fraction in TNZ-MM-1073 and TNZ-MM- 1273 compacts is $54 \pm 15$, and $28 \pm 10$, respectively.

In general, the driving force for continuous grain growth decreases with increasing grain size. Therefore, during sintering at $1273 \mathrm{~K}$, the grain growth rate at the shell may be higher as compared to that of the core. Therefore, it can be presumed that as compared to the core region, significant grain growth occurs in the shell region. As a result, in comparison to the TNZ-MM-1273 compact, the fine grains in the "TNZ-MM-1073 compact" are arranged in a wellconnected network. Also, it can be seen that the core region of TNZ-MM-1273 tends to become single large-sized grain (Fig. 4c). Therefore, it is clear that, with increasing temperature, coarse grains of core tend to consume the finer grains of the shell; and approaching toward homogeneous microstructure.

Tension tests were carried out under uniaxial tensile loadings at room temperature. The tensile properties of various TNZ compacts are shown in Fig. $5 \mathrm{a}$. Also, for the convenient comparison, the strain and strength are plotted, separately, in Fig. 5b, for respective specimens. In addition, the energy absorbed during elastic deformation until the elastic limit known as the modulus of resilience, i.e., elastic energy, was also calculated from the stress-strain curve. The elastic energy of the specimen (Fig. $5 \mathrm{c}$ ) is represented by the area under the elastic region in the stress-strain curve.

The harmonic structured TNZ alloy compacts (TNZ-MM-1073, and 1273) showed higher strengths than conventional homogeneous microstructured TNZ alloy compacts (TNZ-IP-873, 1073, and 1273). However, the corresponding elongation of homogeneous microstructured TNZ compacts was larger as compared to harmonic structured TNZ compacts. For both TNZ-IP and TNZ-MM compacts, it is found that with the increase of temperature from $1073 \mathrm{~K}$ to $1273 \mathrm{~K}$, the tensile strength decreased, which is attributed to the effect of the grain size. In particular, due to the incomplete network structure of the shell region, the strength and elongation to fracture were lower as compared to the TNZ-MM-1073 compact wherein a well-defined continuously connected network of the shell was observed. Therefore, it can be assumed that a connected network structure of fine-grained shell is very crucial in achieving optimized mechanical properties. Moreover, among all, the elastic energy of TNZ-MM-1073 compact is highest and it is about 4 times higher than that of stainless steel $\left(2.41 \mathrm{MJ} / \mathrm{m}^{3}\right)$. The biomechanical compatibility of TNZ compacts was evaluated in terms of elastic admissible strain, which is a material's ratio of yield strength to Young's modulus. As per the Huang et al. [8], Young's modulus of Ti-25Nb-25Zr alloy is $70 \mathrm{GPa}$. Considering the similar value of Young's modulus the elastic admissible strain was estimated for all the TNZ compacts. The elastic admissible strain values for TNZ-IP-1073, TNZ-IP-1273, TNZ-MM-1073, and TNZ-MM-1273 compacts are $0.86 \%, 0.79 \%, 1.07 \%$, and $1.01 \%$, respectively. The fabricated TNZ compacts exhibited elastic admissible strain in the range of $0.86 \%$ to $1.07 \%$ which is higher than those of 316 SS $(0.11 \%)$, Co-Cr (0.23\%) [28], Cp-Ti (0.34\%), Ti6Al-4V (0.80\%) [29], and close to the Ti-28Nb-35.4Zr (CR-ST; 0.9\%-1.2\%) [30]. The TNZ-MM-1073 compact shows a significantly higher elastic admissible strain and higher strength with acceptable
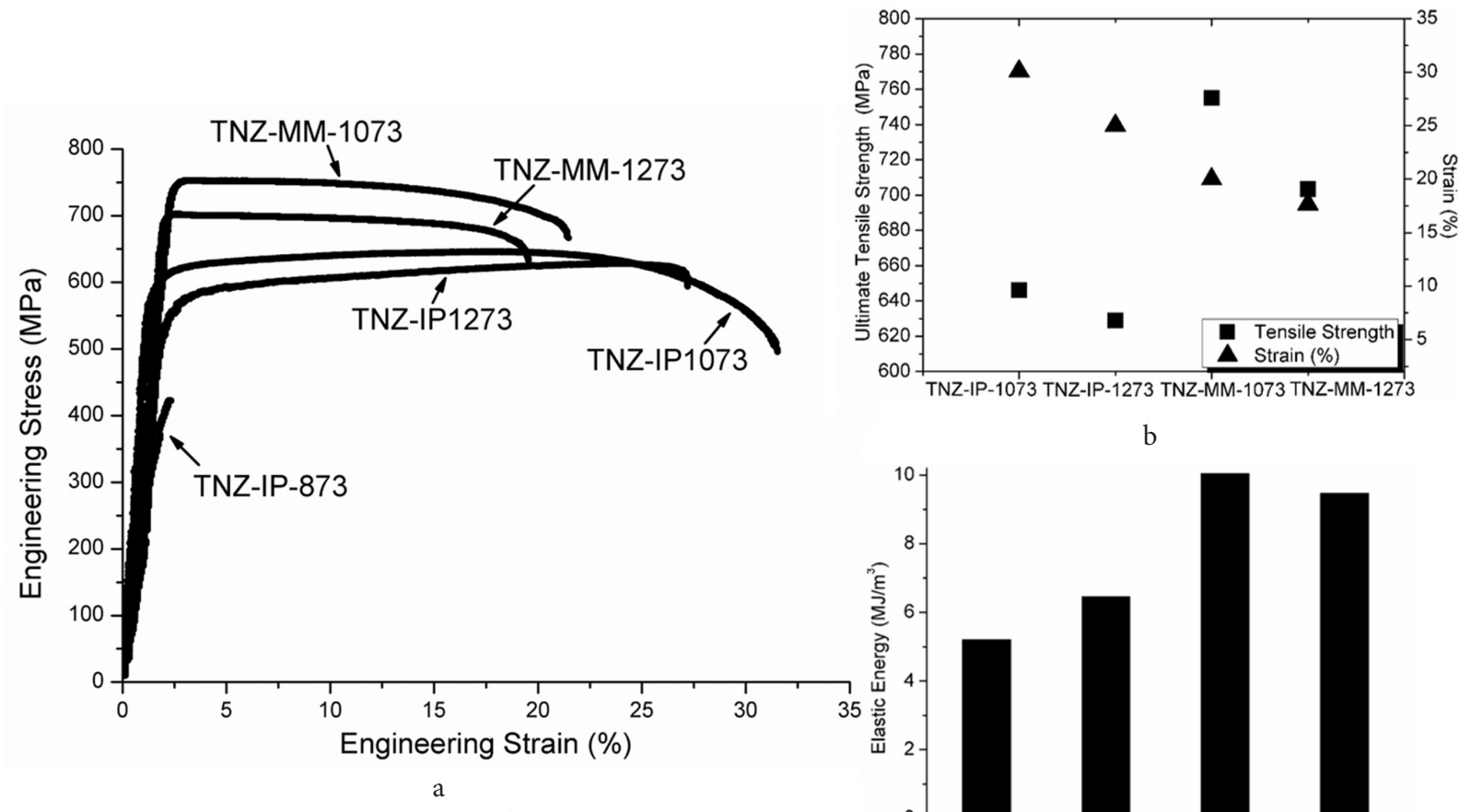

b

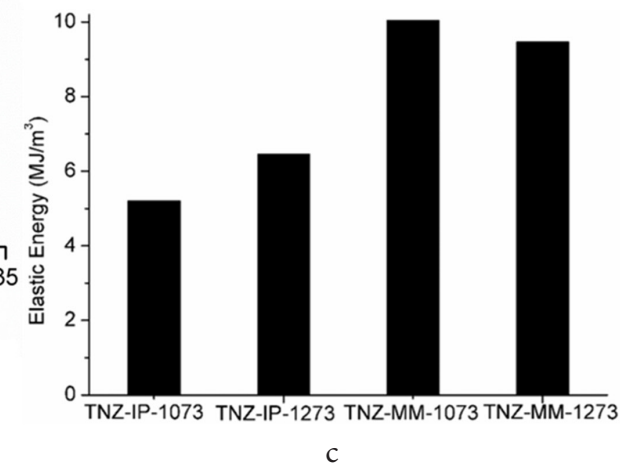

Fig. 5. The representative stress-strain curves (a); and comparison of tensile properties (UTS, and Strain) (b), and Elastic Energy of various TNZ compacts (c). 
elongation, among others. Therefore, it can be considered as a promising material for the orthopedic implant applications.

These outstanding mechanical properties of harmonic structured TNZ-MM-1073 compact might be the result of a well-defined continuously connected network of the shell with fine grains. However, it is remarkable that the higher strength and optimum elongation to break can be achieved by designing the harmonic structure in TNZ compacts. Moreover, depending on the volume fraction of the shell regions, the strength and ductility can be tailor-made as per the requirement of the applications. Therefore, $\beta$ titanium alloys, with tailor-made properties, can be achieved by designing the harmonic structure.

\section{Conclusions}

An investigation was carried out on the role of starting powder conditions, and sintering temperatures, in powder metallurgy process, on the microstructure and mechanical properties of bio-grade $\beta$-type $\mathrm{Ti}-25 \mathrm{Nb}-25 \mathrm{Zr}$ alloy. The Ti-25Nb-25Zr alloy with homogeneous and harmonic structure was successfully prepared from as-received Ti-25Nb-25Zr powder and mechanically milled (72 ks) powders, respectively.

The controlled mechanical milling of pre-alloyed PREP $\mathrm{Ti}-25 \mathrm{Nb}-25 \mathrm{Zr}$ powder led to the formation of a bimodal microstructure in the milled powder particles, consisting of severe plastic deformed powder surface and the un-deformed inner region. In sintered compacts, the severely deformed powder surface regions form a three-dimensional network of fine grains ("Shell"), surrounding the coarse-grained ("Core") areas, leading to the formation of "Harmonic Structure".

Sintering of powder at lower temperatures (873 K) resulted in fine-grained $\mathrm{Ti}-25 \mathrm{Nb}-25 \mathrm{Zr}$ compacts with a significant amount of porosity. However, at higher sintering temperatures of 1073 , and $1273 \mathrm{~K}$, no porosity was observed. The TNZ compact prepared at $873 \mathrm{~K}$ exhibit poor mechanical properties whereas the compacts prepared at higher temperature exhibited good mechanical properties. In particular, the harmonic structured $\mathrm{Ti}-25 \mathrm{Nb}-25 \mathrm{Zr}$ alloy, prepared at $1073 \mathrm{~K}$, exhibited a good combination of strength and ductility as compared to the TNZ compacts having homogeneous microstructure.

Acknowledgments. This work was supported by Grantsin-Aid for "Scientific Research on Innovative Areas on High Entropy Alloys" through the grant number 18H05455, and JSPS KAKENHI Grant Number JP18K18962.

\section{References}

1. Y. Fukuzumi, T. Wada, H. Kato. Surface Improvement for Biocompatibility of Ti-6Al-4V by Dealloying in Metallic Melt. In: Interface Oral Health Science 2014 (ed. by K. Sasaki, O. Suzuki, N. Takahashi). Springer, Tokyo (2015) pp 93-101. Crossref

2. M. Niinomi. Science and Technology of advanced materials. 4, 445 (2003). Crossref

3. J.Y. Rho, T.Y. Tsui, G.M. Pharr. Biomaterials. 18 (20), 1325 (1997). $\underline{\text { Crossref }}$
4. H. C. Hsu, S. C. Wu, Y. C. Sung, W. F. So. J. Alloys Compd. 488, 279 (2009). Crossref

5. M. V. Oliveira, L. C. Pereira, C. A. A. Cairo. Mater. Res. 5, 269 (2002). Crossref

6. E.D. Spoerke, N.G. Murray, H. Li, L.C. Brinson, D. C. Dunand, S. I. Stupp. Acta Biomaterialia. 1 (5), 523 (2005). Crossref

7. M. Geetha, A. K. Singh, R. Asokamani, A. K. Gogia. Pro. in Mat. Sci. 54, 397 (2009). Crossref

8. H.H. Huang, C. P. Wu, Y.S. Sun, H. M. Huang, T. H. Lee. Thin Solid Films. 549, 87 (2013). Crossref

9. H.H. Huang, C. P. Wu, Y.S. Sun, W. E. Yang, M.C. Lin, T. S. Lee. Surface and coating technology. 259, 206 (2014). Crossref

10. J.H. Chang, J.F. Liu, Y.S. Sun, C.P. Wu, H.H. Huang, Y. Han. Journal of Alloys and Compounds. 707, 220 (2017). $\underline{\text { Crossref }}$

11. S. K. Vajpai, B. Sharma, M. Ota, K. Ameyama. Materials Scienceand Engineering: A. 736, 323 (2018). Crossref

12. M. Hayakawa, O. Kanou, N. Fukada. J. Japanese Society of Powder Metallurgy. 63 (7), 497 (2016). $\underline{\text { Crossref }}$

13. G. Lütjering, J. C. Williams. Titanium, 2nd edn. Springer Berlin Heidelberg, New York (2007) pp. 86-99.

14. A. Couret, G. Molénat, J. Galy, M. Thomas. Intermetallics. 16 (9), 1134 (2008). Crossref

15. L. L. Ye, Z. G. Liu, K. R. Prasad, M.X. Quan, M. U. Memoto, Z. Q. Hu. MSE-A. 241 (1-2), 290 (1998). Crossref

16. B. Liu, S. Huang, L. Chen, J. V. Humbeeck, J. Vleugels. Mat. Letters. 191, 89 (2017). Crossref

17. M.A. Hussein, C. Suryanarayana, N. Al-Aqeeli. Mat. and Design. 87, 693 (2015). $\underline{\text { Crossref }}$

18. S. Kikuchi, H. Akebono, A. Ueno, K. Ameyama. Powder Technology. 330, 349 (2018). Crossref

19. S. Kikuchi, Y. Hayami, T. Ishiguri, B. Guennecc, A. Ueno, M. Ota, K. Ameyama. MSEA. 687, 269 (2017). Crossref

20. M. O. Kawabata, K. Ameyama. Journal of the JSTP. 58 (678), 563 (2017). Crossref

21. F. H. Froes Sam. Powder metallurgy of titanium alloys In: Advances in Powder Metallurgy. Woodhead Publishing (2013) pp. $202-240 . \underline{\text { Crossref }}$

22. H. Fujiwara, H. Inomoto, K. Ameyama. Tetsu-to-Hagané. 91, 839 (2005). Crossref

23. M. Umemoto, K. Tsuchiya, Z.-G. Liu. J. Jpn. Soc. Powder Metallurgy. 50, 189 (2003). $\underline{\text { Crossref }}$

24. S. K. Vajpai, M. Ota, T. Watanabe, R. Maeda, T. Sekiguchi, T. Kusaka, K. Ameyama. Metallurgical and Materials Transactions A. 46 A, 903 (2015). Crossref

25. D. L. Zhang. Progress in Materials Science. 49, 537 (2004). $\underline{\text { Crossref }}$

26. K. Williamson, W.H. Hall. Acta Metall. 1(1), 22 (1953). $\underline{\text { Crossref }}$

27. M. Niinomi, T. Akahori. Expert Rev. Med. Devices. 7, 481 (2010). $\underline{\text { Crossref }}$

28. F. W. Crooke, J.E. Lemons, B.D. Ratner. Properties of Materials. In: Biomaterials Science. Academic Press, San Diago (1996) pp. 11-35. Crossref

29. K. Wang. Materials Sci. Eng. A. 213 (1-2), 134 (1996). Crossref 30. S. Ozan, J. Lin, Y. Li, Y. Zhang, K. Munir, H. Jiang, C. Wen. Journal of Mechanical Behavior of Biomedical Materials. 78, 224 (2018). $\underline{\text { Crossref }}$ 